\title{
Por uma fenomenologia da opinião
}

\author{
Francisco Jozivan Guedes de Lima* \\ Agemir Bavaresco** \\ Oscar P. Portales ${ }^{* * *}$
}

DOI 10.20399/P1982-999X.2016v1n2pp94-115

\begin{abstract}
Resumo
A opinião pública explicita a dialética dos interesses individuais e sociais. Há o conflito na opinião privada que se legitima pela esfera social e se reconhece no espaço público. A opinião pública resolve a sua contradição a partir da construção de estruturas sociais que elevam a singularidade a uma particularidade universalizada. Uma base conceitual para o estudo desse paradoxo encontra-se no pensamento hegeliano. Hegel descreve na Fenomenologia do Espírito o processo da consciência do sujeito que opina. A evolução da experiência da consciência privada e pública se reflete nas figuras históricas. A experiência da consciência de opinar é um fenômeno contraditório. A dialética dessa contradição manifesta-se, atualmente, a partir da emergência das redes sociais
\end{abstract}

Palavras-chave: Opinião Pública; Fenomenologia; Redes Sociais.

\begin{abstract}
Public opinion explains the dialectic of individual and social interests. There is conflict in the private opinion that legitimizes the social sphere and it is recognized in the public space. Public opinion resolves its contradiction with the construction of social structures that elevate the singularity to a universalized particularity. A conceptual basis for the study of this paradox lies in the Hegelian thought. Hegel describes in the Phenomenology of the Spirit the process of consciousness of the subject who opines. The evolution of the experience of private and public awareness is reflected in historical figures. The experience of consciousness of an opinion is a contradictory phenomenon. The dialectic of this contradiction manifests itself currently from the emergence of social networks.
\end{abstract}

Key-words: Public Opinion; Phenomenology; Social networks.

\section{Introdução}

O século XX esteve caracterizado pela evolução duma sociedade civil com espaços sociais articuladores dos interesses privados e públicos. Essa articulação orgânica do privado e público esteve definida claramente pela participação, consumo ou a alienação dos referidos espaços mediante votações, associações e o fluxo dos meios de comunicação. As dinâmicas do mercado encarnaram as conflitantes necessidades do intercâmbio e da alienação dos concorrentes. A opinião pública refletia essa dialética de representações dos interesses e interpretações pelas instituições acerca das dinâmicas individuais e sociais. Nesta se dá o processo de conflito entre a opinião privada que deve se legitimar no intercâmbio duma esfera social e do seu reconhecimento ou alienação no espaço público. A opinião pública se caracteriza pela resolução dessa contradição a partir de dinâmicas de utilidade alienantes da esfera privada impondo a

\footnotetext{
* Professor do Departamento de Filosofia da Universidade Federal do Piauí (UFPI). Doutor em Filosofia pela Pontifícia Universidade Católica do Rio Grande do Sul (PUCRS). E-mail: jozivan2008guedes@gmail.com Lattes: http://lattes.cnpq.br/8231159547990641

** Professor do Departamento de Filosofia da PUCRS. Doutor em Filosofia pela Universidade de Paris I (Pantheon-Sorbonne). E-mail: abavaresco@ pucrs.br Lattes: http://lattes.cnpq.br/6597683266934574

*** Mestrando em Filosofia pela PUCRS. Lattes: http://lattes.cnpq.br/6292695504185486
} 
sociabilidade, ou noutro sentido a partir da construção de estruturas sociais que subordinam a singularidade a uma particularidade universalizada.

No século XXI a análise crítica deste processo é ainda mais complexa. O surgimento das redes sociais tem criado uma nova esfera de exposição destas contradições. Estas se articulam a partir de um espaço notadamente privado de opiniões que se articula numa esfera social. Mas esse processo que no passado era definido a partir da contradição em relação a estruturas institucionais definidas, agora ocorre num espaço privado. Este tem sido espaço de expressão de interesses públicos comumente esquecidos e silenciados pelos meios de comunicação institucional. Os referidos interesses têm se articulado na consciência pública vertida em marchas e movimentos de transformação alternativa. Mas também tem sido um espaço de alienação das consciências particulares numa lógica utilitária universal. Nesta se expressa então a mesma disjuntiva de como estruturar a relação entre o privado e o público num processo em que esta dinâmica de evolução da opinião seja parte dum saber dialético enquantorarítberse conceitual para o estudo desse paradoxo encontra-se no pensamento hegeliano. Na Fenomenologia do Espírito, Hegel descreve o processo da consciência do sujeito que entra em relação com o mundo como um objeto que ele se dá mediante um processo de evolução da experiência da consciência privada e pública e da passagem à objetivação que se traduz nas figuras históricas do espírito. O desenvolvimento da consciência e a experiência que ela faz enquanto relações contraditórias entre sujeito e objeto fazem aparecer o fenômeno da opinião num percurso lógico da consciência que se torna um saber dialético, criando no espaço público as condições de afirmação da opinião pública enquanto tal. Daí que a opinião pública como fenômeno expresse a estrutura contraditória que se operacionaliza na evolução da consciência.

O sistema hegeliano de exposição da experiência da consciência de opinar permite compreender a opinião pública como fenômeno contraditório. Contudo permitiria na atualidade a compreensão dialética dessa contradição na esfera privada na qual se manifesta a partir do surgimento das redes sociais. Nestas se expressam de um modo alternativo, livre e heterogêneo os diversos tipos de opinião sem uma triagem repressora.

\section{A experiência da consciência do opinar}

Num primeiro momento a consciência está só; ela não se opõe a um objeto (Gegenstand). A consciência se define frente a "coisa" que é a multiplicidade ante a qual existe. Ter noção do que é como consciência própria consiste em ter certeza de si, e tendo noção do outro. Ser é opinar: perante a consciência se revela o que não é privado como coisa pública, algo que nega, mas que ao mesmo tempo é espaço de efetivação de si. Aqui se opera a unidade dos dois momentos - consciência e autoconsciência - postos como consciência pública. Face ao mundo "público" a consciência reage opinando publicamente. Se a contradição da consciência reflete a tensão entre privado e público como determinidade, a tarefa consistirá na exposição de vias de constituição da consciência publica a partir dessa contradição e nesse percurso define-se o evoluir da opinião pública. Para Hegel a opinião é incluída na consciência e salva pela mesma; ela faz parte da experiência da consciência e por esta a 
opinião é elevada à verdade do "público". O percurso do espírito consiste em elevar a certeza da opinião até a verdade. A existência do fenômeno na consciência é a relação formal, e é apenas certeza; o objeto é determinado somente de modo abstrato. O espírito, para elevar-se da certeza à verdade, passa por degraus no desenvolvimento da contradição entre o público e o privado na opinião.

\section{Como se processa a consciência na Certeza Sensível}

Num primeiro nível a consciência enquanto relação contém somente as categorias que pertencem ao Eu abstrato. Como consciência sensível conhece seu objeto como um ente público singular e como certeza sensível está aberta acolhendo o conteúdo da realidade. Sente a si mesma e sente o material público como singular exterior determinado por ela, no espaço e no tempo, um aqui e um agora. Mas a consciência levada pela existência duma universalidade múltipla no público deve se confrontar com formas finitas em que se desenvolve a partir desta certeza sensível.

A consciência experimenta o objeto como o essencial e o Eu como o inessencial. É preciso, portanto, apreender esse objeto público segundo a forma sob a qual a certeza sensível o conhece. A consciência como certeza sensível considera o objeto como um "isso": o "agora" e o "aqui". A afirmação do universal se localiza na linguagem enquanto que a opinião permanece ainda prisioneira de uma certeza singular. Para a opinião, o isso público persiste como um agora e um isso indiferente, pois ela não é capaz de se midiatizar ou de se universalizar. O resultado desta primeira experiência é uma inversão, pois o objeto se torna o inessencial e o Eu torna-se o essencial que contém o universal.

$\mathrm{Na}$ imediatidade do $\mathrm{Eu}$, por outra parte, a certeza sensível relaciona-se com o sujeito ou com o Eu. Nisso a experiência do Eu não desenvolve a universalidade daquele sujeito. O "agora" e o "isso" desaparecem um no outro, mas o Eu permanece o mesmo como o universal que mediatiza o isso. O Eu singular expressa o Eu universal, mas a opinião não é capaz de expressar o universal, pois ela opina somente sobre o imediato. Nesse evoluir da certeza sensível o ato de opinar é um inessencial, pois o objeto e o Eu são dois universais nos quais o agora e o isso da opinião nem são, nem permanecem, mas se diluem. A certeza total tenta manter, o objeto e o Eu imediatos, além de sua oposição, mas esta relação imediata é um processo ou um movimento que passa pelo ato de indicar ${ }^{2}$. A experiência da consciência sensível é o movimento dialético entre o Eu e o objeto. A opinião considera inicialmente o objeto como o verdadeiro, depois a consciência coloca na opinião o saber verdadeiro. A opinião é o movimento de ir em direção ao objeto ou ao sujeito. $\mathrm{O}$ opinar e a linguagem têm o mesmo objeto público: o primeiro o apreende enquanto singular e individual, e o segundo como o universal. A opinião dirige-se ao imediato que é inacessível à linguagem e a linguagem indica já o universal e, quando a consciência toma o objeto deste modo, ele não é mais o saber imediato, mas o ato de percepção.

\footnotetext{
1 "Um tal simples que é pela negação, nem isso nem aquilo, um não isso, e igualmente indiferente a ser isso que aquilo, nós o nomeamos um universal; o universal é, portanto, de fato o verdadeiro da certeza sensível". (HEGEL, G. W. F. Fenomenologia do Espírito. Petrópolis: Vozes, 1992, p. 150).

2 "O indicar é, então, o movimento que anuncia isso que o agora é de verdade; a saber um resultado, ou uma multiplicidade de agora reunidos; e o indicar é o experimentar que agora é [um] universal". (Ibidem, p. 155).
} 


\section{Consciência e percepção}

O objeto da consciência sensível muda, torna-se uma coisa percebida como contento e uma multiplicidade de propriedades. Torna-se uma diversidade de relações, de determinações de reflexão, de determinações lógicas - o singular múltiplo -, que são postas pelo sujeito que pensa, pelo Eu. A consciência começa a perceber o objeto como mediatizado, refletido nele mesmo e universal, como conexão contraditória de determinações sensíveis e de determinações de pensamentos. Metafisicamente falando, a contradição é constituída em seu conteúdo pela substância e suas propriedades variadas, isto é, os acidentes. O "isso" que é a comunidade torna-se uma "coisa' para a percepção. A comunidade não é um todo uniforme. A consciência perceptiva toma a coisa nas suas contradições, pois ela descobre que o público é, ao mesmo tempo, um singular e um universal.

$\mathrm{O}$ ato de perceber faz progredir o que é sensível até conectá-lo a um universal. A consciência começa a conhecer cada realidade isolada em sua verdade singular. A consciência sensível indica as coisas, ela mostra a imediação do espírito público, enquanto que a percepção toma a articulação da coisa pública em sua contradição. É uma opinião esclarecida que ultrapassa o singular imediato que é capaz de perceber o público como universal segundo uma contradição ainda insuficientemente mediada.

\section{Consciência e Entendimento}

Perante a percepção, a consciência enquanto entendimento compreende o objeto em sua dualidade. Ela confronta a força ${ }^{3}$ que compõe o objeto e o fenômeno que inclui nele um suprassensível, a mesma força das leis que regem o dinamismo do objeto ${ }^{4}$. Dá-se assim a interação de duas forças que surgem como independentes e, em seguida, tornam-se uma ação recíproca. A força enquanto vontade social ou política é o dinamismo das instituições públicas que se apresenta como fenômeno público; o entendimento faz a experiência do objeto público como uma relação de forças em que se opera a dialética entre as instituições e os diferentes grupos sociais e toma-o como uma lei interior, como essência do fenômeno, enquanto determinação do entendimento que é conforme ao interior ou a essência do objeto. Para Hegel, a lei que está no interior do fenômeno diferencia-se e move-se como a vida.

\footnotetext{
3“'A força, tal como o entendimento a apreende na sua complexidade objetiva, exprime sua universalidade na articulação de seus momentos constitutivos - o Um e o subsistir das matérias. Esses momentos, porque são os extremos de um movimento de reflexão, são aqui tratados segundo a economia do interior e do exterior; o entendimento fará a experiência de sua pressuposição mútua". (HEGEL, 1992, p. 180-181, nota 1$)$.

4 "Na primeira Lógica de Iena a relação da coisa a suas propriedades (percepção) corresponde à relação da substância aos acidentes, à relação da força à sua exteriorização corresponde à relação de causalidade. A ideia de força exprime a impossibilidade de separar a causa e o efeito. Nós passamos, então, do substancialismo ao dinamismo". (Ibidem, p. 11, nota 5). O jogo das forças faz parte do fenômeno que Hegel tomou do conceito de força da física dinâmica da época com seu jogo de atração e de repulsão; assim como a força positiva e negativa que compõe a eletricidade.
} 
A consciência como o entendimento tem um conhecimento das leis e relacionase com o objeto público no qual o Eu encontra o duplo de seu próprio objeto. Mas a consciência dependendo do entendimento não pode conceber a unidade da lei nem determinar dialeticamente sua oposição. A unidade do entendimento não se harmoniza com a atividade do Eu. No ser vivo a consciência intui o processo da lei, isto é, a posição e a suprassunção das determinações diferentes. A diferença não é absolutamente fixa, pois a vida é uma existência sensível, exterior e ao mesmo tempo absolutamente interior; o ser vivo é um existente material composto de exterioridade recíproca. A vida deve se transformar no seu próprio fim que tem nele mesmo seu meio e sua totalidade na qual cada elemento diferenciado é simultaneamente meio e fim. Ora, esta unidade dialética vivente - a consciência idêntica e diferenciada - é a autoconsciência ${ }^{5}$.

Em nível de movimento do todo a Fenomenologia, a "força e o entendimento" são um novo percurso do itinerário já feito nas duas dialéticas anteriores. Agora, o objeto é suprassumido no universal e o resultado é a infinitude como a contradição pura e o movimento sem repouso. A consciência não se põe mais sob um modo objetivo, mas como experiência de si, como um Eu que se reflete e toma a si mesmo como objeto: é a autoconsciência.

\section{Da autoconsciência privada à autoconsciência pública ${ }^{6}$}

A experiência de toda consciência consiste na capacidade de o Eu conhecer o objeto na representação como seu que é a primeira forma abstrata de autoconsciência que é verdade abstrata, idealidade pura e negação de si. Assim, a contradição é suprassumida e posta na identificação da consciência e da autoconsciência. A autoconsciência eleva-se à identidade de um Eu capaz de reconhecer as instituições públicas como suas, e ele mesmo se encontra no público; a autoconsciência tem nela mesma o espírito público. Aqui a autoconsciência abstrata e a consciência são ainda duas coisas diferentes. Essa diferença forma uma contradição interna na autoconsciência que contém uma realidade imediata e exterior oposta a uma interioridade sem diferença. A resolução desta contradição passa pelo desenvolvimento do $\mathrm{Eu}$ abstrato como diferença real, e por aí o sujeito unilateral é suprassumido e determinado como um mundo público. Pensando-se a partir de um processo inverso, o mundo público é interiorizado no sujeito, ou seja, o mundo é posto mediante um Eu. Neste processo a dependência da consciência em relação ao mundo desaparece. A autoconsciência agora contém a consciência e seu mundo exterior ligados e dissolvidos nela mesma.

\section{A experiência da opinião pública contra o individualismo moderno}

\footnotetext{
${ }^{5}$ Enc, III, $\S 142$, adição, p. 526 e $§ 423$, adição, p. 527.

${ }^{6}$ Nós adotamos este termo "autoconsciência" seguindo a tradução feita por G. Jarczyk e P.-J. Labarrière e a justificação precisa e sólida que eles dão e que nos citamos aqui: "No que diz respeito ao termo "autoconsciência", pode-se afirmar que ele é largamente admitido em nossa língua. Falando em "Selbstbewusstsein", Hegel entende designar o movimento pelo qual a "consciência", realidade essencialmente dual, toma-se ela como objeto de seu saber; o movimento de reflexão pelo qual o "Eu" originário (o "Ich", visado na sua qualidade de sujeito, como ponto de partida de um processo de sentido) retornou nele mesmo carregado de objetivação que se deu na linguagem ou no trabalho, e pode ser nomeado um "Si" (um “Selbst”). (HEGEL, 1992, p. 55-56).
} 
A evolução de noções e dinâmicas pensadas como algo público tem origem nas realidades grega e romana antigas, mas sua vinculação com processos em torno da "sociedade civil" e a sua separação frente aos espaços privados remonta à Europa do século XVII. É também a partir deste momento que descrevem um ascendente decurso de formulação teórica, construção institucional e de complexificação social oriundas de transformações nas estruturas econômica, político-institucionais e simbólicas.

A modernidade gerou o princípio do individualismo como estrutura organização produtiva e simbólica. Ela converteu o indivíduo na célula básica de modelo de confluência gerando um espaço novo onde o mercado passou a ser o mediador das relações intersubjetivas e foi instaurada uma dinâmica histórica ao processo de secularização do exercício do poder ${ }^{7}$. O processo de afirmação individual de interesses tem por consequência a afirmação do espaço da concorrência que emerge como oposição e realização do privado e gera a coisa pública. Diferente da res publicae romana, no início da modernidade o público se pauta na liberdade absoluta, pelo menos formal, de todos os concorrentes opostos ao poder do Estado absoluto ${ }^{8}$.

A ascensão ao poder político da burguesia implicou mudanças nesses processos afirmativos do público. A institucionalização do Estado como instrumento ${ }^{9}$ secularizado constituiu um elemento de delimitação do público como característica dum conglomerado institucional ${ }^{10}$. Vários pensamentos contestaram essa identidade mediante uma distinção antiga entre o público e o privado a partir da participação na polis e da orientação do poder, e da distinção entre o interesse de uns e o interesse da maioria. Essa perspectiva situa o público como dinâmica de interrelação do privado e do poder político em que este último deve orientar a sua progressiva transformação em público. Essa distinção assinala que o caráter público não depende dos espaços ou dos aparelhos institucionais de organização de intersubjetividade, mas que depende do caráter do exercício do poder político em função dos interesses privados ou sociais. Habermas situa o público além do institucional como dialética do relacionamento entre as opiniões privadas e coletivas ${ }^{11}$. Neste sentido o público pode ser analisado como dever ser do relacionamento social dirigido à substituição do poder político pelo poder público, como ordenamento advindo da deliberação das individualidades ${ }^{12}$.

\section{O espírito objetivo ou a gênese do espírito público da opinião}

$\mathrm{Na}$ crise da sociedade feudal aparece a representação da opinião e as instituições adquirem valor como algo relativo ao bem comum ${ }^{13}$. Efetivam-se em sujeitos particulares como no rei e no senhor, valores universalmente

\footnotetext{
${ }^{7}$ ACANDA, Jorge Luis. Sociedad civil y hegemonía. Habana: Centro de Investigación y Desarrollo de la Cultura Cubana Juan Marinello, 2002, p.109.

${ }^{8}$ HABERMAS, J. El discurso filosófico de la modernidad. Madrid: Taurus, 1993.p.20

${ }^{9}$ Ibidem. p. 108.

${ }^{10}$ HABERMAS, J. Historia y critica de la opinión pública. Barcelona: Ediciones G. Gili, 1994. p.44.

${ }^{11}$ Ibidem, p. 44.

12 Ibidem, p. 151 .

${ }^{13}$ Ibidem, p. 45.
} 
compartilhados que não são o patrimônio duma ação privada ${ }^{14}$. Na Inglaterra do século XVII dá-se o início da mediação do poder do rei que tem o título de publicness $^{15}$. No século XVIII com o absolutismo e o surgimento dos Estados a nobreza perde seu caráter de representação da opinião ${ }^{16}$. A troca das informações se desenvolve em ligação com as necessidades das trocas das mercadorias. Em oposição a imprensa passou a ser usada pelo Estado monárquico que reclamava o monopólio do público ${ }^{17}$. A opinião expressa na corte pela vontade do rei terá que enfrentar o desafio da publicidade gestada em ambientes burgueses nos salões, no café, nos clubes de escritores, etc. A gênese da esfera pública burguesa é o espírito alienado de si que a Fenomenologia descreve como o mundo da cultura. Hegel utiliza nesse desenvolvimento uma categoria chave que é a alienação - "Entfremdung"18. O Iluminismo escocês, por exemplo, representa a sociedade civil como o espaço de autoconstituição da individualidade ${ }^{19}$. Hegel critica esta fundamentação que nos apresenta o mundo da utilidade como o momento da verdade da cultura e da fé.

As revoluções burguesas do final do século XVIII foram o esforço de construção duma publicidade que reconhecera a opinião pública advinda do direito privado de $\operatorname{opinar}^{20}$. O público foi reconhecido como um espaço não estatal que deve ser protegido pelo poder institucional permitindo o livre arbítrio da razão. Portanto, a "pura inteligência" torna-se uma consciência efetiva e satisfeita de modo que a objetividade alcançada constitui seu mundo. A análise hegeliana é crítica da verdade do "Iluminismo" que se impõe no conceito da utilidade ${ }^{21}$. A opinião pública está onde não há poder estatal; ela é a opinião de quem não tem meios político de expressão. Ou seja, a crítica não deve ser feita à opinião pública moderna em si, mas à sua orientação comercial e individualista dada pela burguesia que visava tal como o absolutismo a apropriação da coisa pública.

Após as revoluções burguesas de 1848 o Estado é representado como função instrumental da sociedade burguesa que é a representação da publicidade de todos ${ }^{22}$. A secularização do Estado configurou-o como representante do público, perante o qual a livre publicidade do indivíduo deve se submeter ${ }^{23}$. A luta para impor o caráter público

\footnotetext{
${ }^{14}$ As cortes francesas e borgonhesas surgidas no século XV serão os últimos bastiões desta. A figura do "cortesão" formado pelo Humanismo suplanta o cavaleiro cristão.

15 Ibidem, p. 46.

${ }^{16}$ Esse processo se faz evidente com a transformação demográfica que separa e opõe a Corte e a cidade. (Ibidem, p. 37).

17 Num edito do ano 1784 diante a evolução da imprensa, Frederico II, condenava as opiniões qualificadas de "públicas" por referência a uma esfera pública que era considerada como o domínio próprio do poder. (HABERMAS, 1994, p. 63).

${ }^{18}$ BAVARESCO, Agemir. Fenomenologia da Opinião Pública. São Paulo: Loyola, 2003, p. 63.

${ }^{19}$ No pensamento do Adam Smith a sociedade civil, com seu foco na atividade econômica, é o resultado da necessidade do reconhecimento, consequência da sociabilidade.

${ }^{20}$ São paradigmáticos no caso da revolução francesa o "Juramento do Jogo da Bola" do 20 de junho de 1789, assim como os exemplos das brigas entre a Rinha Maria Antonieta e a cidade de Paris pela sua incapacidade comunicativa.

${ }^{21}$ Ainda no exemplo da Alemanha do século XVIII, na qual não pode se comparar a cidade oposta a corte, as esferas de opinião já reassentam um demiurgo de concorrência na igualdade. (HABERMAS, 1994, p. 45).

${ }^{22}$ ACANDA, 2002, p. 124.

23 É significativa neste momento a proibição de manifestações, expressão em periódicos de setores sindicais e camponeses, em nome da própria publicidade. (LOSURDO, D. Hegel Marx e la tradizione liberale. Roma: Editori Riuniti, 1998, p. 93-95).
} 
do Estado e da opinião passa pelo crivo classista da propriedade ${ }^{24}$. A sociedade civil se considerava separada do estado de natureza; a opinião pública implicava a subordinação ao espaço das estruturas do Estado e o exercício da opinião era privativo dos cidadãos ativos ${ }^{25}$.

O século XIX é o cenário de novas tensões sociais, pois nele a Estado é reclamada pela sociedade civil. Não era suficiente nem o refúgio opinião privada, nem a simples subordinação a razão universal da publicidade Porém na ideia de Hegel o sujeito moral está agora certo de conseguir reunir em universalidade pública e a singularidade privada como certeza na ação moral. A pública institucionalizada e a linguagem da opinião pública são reunidas na ação do sujeito moderno como consciência pública do indivíduo privado. Em Hegel instituições da publicidade não contêm a opinião pública, haja vista esta ser um entendimento humano que integra o opinar subjetivo e a objetividade ${ }^{27}$.

A ampliação social dos direitos políticos no final do século XIX e no implicou a necessidade de mediadores entre a soberania da sociedade civil e sua representação pelo Estado. Partidos, meios de comunicação, organizações agremiações, pesquisas eleitorais e de popularidade governamental, fariam essa mediação configurando uma "publicidade politicamente ativa" 28 e representativa opinião pública. É significativa a crescente participação do Estado no espaço assunção por corporações privadas de funções públicas que socializaram os riscos do capital e seus custos na sociedade em seu conjunto ${ }^{29}$. A sociedade de massa criada a partir dessa mediação significou um avanço na expressão da opinião pública, mas também implicou a neutralização da publicidade pela representação institucional.

A opinião dos meios de comunicação parecia não alterada pela propriedade, pelo poder político, pela ideologia profissional ou pela influência de grupos coorporativos específicos. Assim se gerou um sistema de consumo que limitou a capacidade de afirmação da opinião privada ${ }^{30}$. Desta forma o público volta a ser a totalidade duma opinião fora do sujeito à qual este subordina sua constituição consciente. Essa mediação entraria em crise com "o mundo de pós-guerra" 31 no qual Bourdieu critica a opinião pública encarada como resultado das técnicas de pesquisa e como quantificação ${ }^{32}$. Habermas questiona o caráter público da opinião pela impossibilidade de acesso aos meios de criação e expressão da opinião ${ }^{33}$. A partir daí haverá uma nova exigência: o

\footnotetext{
${ }^{24}$ HABERMAS, 1994, p. 123.

${ }^{25}$ Ibidem, p. 147.

26 ACANDA, 2002, p. 142.

${ }^{27}$ HABERMAS, 1994, p. 154.

${ }^{28}$ Ibidem, p. 116.

${ }^{29}$ Este elemento é colocado por Habermas na crítica da divisão entre o privado e o público em sua dimensão só espacial, destacando o enfoque de Hegel entorno a opinião como um processo humano de conhecimento objetivo. (Ibidem, p. 154).

${ }^{30}$ Ibidem, p. 192.

31 LÓPEZ, Guillermo. "Comunicación en red y mutaciones de la esfera pública" http://www.ehu.eus/zer/hemeroteca/pdfs/zer20-11-lopez.pdf.p.241.

${ }^{32}$ BOURDIEU, P. La opinión pública no existe. Paris: Les temps modernes 318, 1973.

${ }^{33}$ HABERMAS, 1994, p.154.
} 
exercício da publicidade estará determinado pela possibilidade de gerar e publicar conhecimento verdadeiro de interesse comum ${ }^{34}$.

\section{A opinião pública e as conexões em rede}

Estes elementos se transformam com a opinião em redes, ocasionando a reformulação das críticas e posicionamentos teóricos em torno a opinião pública ${ }^{35}$. A pública $^{35}$. A partir da década de 70, as revoluções eletrônicas e cibernéticas impuseram impuseram novos espaços de geração, consumo e intercâmbio de conhecimento e e opiniões. Surge uma sociedade baseada no consumo e produção de conhecimento conhecimento caracterizada por sua circulação em redes; passam a existir sociedades sociedades em rede ou sociedades do conhecimento feitas para agir com base na circulação de informação. Essa lógica de rede converte a publicidade e a opinião em em fator substantivo da reprodução social caraterizada pela circulação de conhecimento conhecimento e opiniões ${ }^{36}$. O surgimento tecnológico de softwares e hardwares, telecomunicações, radiodifusão e eletrônica, PCs (personal computers) e a telefonia celular serviu de base para esse processo de conexão. $O$ surgimento da internet e a sociedade em rede coincidem com a crise do sistema capitalista desta década. Esta sociedade em rede gera a interface entre campos tecnológicos e sociais com a conseguinte descentralização do conhecimento.

Os meios digitais expandem a quantidade de conhecimento e possibilitam sua difusão de forma horizontal. A dilatação do tempo de suas análises permite a interatividade de diferentes juízos instantâneos por diferentes sujeitos ${ }^{37}$. Doravante, os pensamentos e palavras não são consumidos só no sentido do sistema de referência homogêneo das culturas de massas, mas podem descrever dinâmicas múltiplas ${ }^{38}$. Esse processo alternativo traz consigo o ressurgimento da capacidade de gerar publicidade e opinião pública à margem da opinião política ativa e seletiva ${ }^{39}$.

As redes sociais têm gerado a possibilidade de criar laços de intercâmbio de opiniões perante uma realidade caracterizada pela polarização social ${ }^{40}$; a partir daí são redefinidos os relacionamentos entre sexos, segmentos etários e étnicos, e transmutados gradativamente padrões culturais dantes inalterados ou monopolizados. As sociedades civis criaram outros espaços de opinião que refletiram seus interesses impactando as dinâmicas privada e pública do processo de opinar. A irrupção dos computadores, celulares, internet e por último as redes sociais potencializaram a ação direta do cidadão como agente igualitário perante meios coorporativos e instituições estatais de opinião centralizadores e excludentes. Valores não expostos pela publicidade institucional

\footnotetext{
${ }^{34}$ Garcia sinala como o século XX gera a opinião pública como a opinião publicada, tendo como centro os meios de publicação (Cf. GARCIA, Juan Antonio: "La opinión publica en la sociedad de la información: un fenómeno social en permanente cambio". http://dialnet.unirioja.es/servlet/articulo?codigo=3813224, 2015. p. 275.

${ }^{35}$ HABERMAS, J. Textos y contextos. Barcelona: Ariel, 1991.

${ }^{36}$ CASTELL, Manuel. A sociedade em rede. São Paulo: Paz e Terra, 2006, p.108.

${ }^{37}$ KASTRUP, Virginia. Novas tecnologias cognitivas: o obstáculo e a invenção. In: LÉVY, Pierre. Ciberespaço um Hipertexto. Porto Alegre: Artes e Oficio, 2000, p.49.

${ }^{38}$ LÉVY, 2000, p.32.

${ }^{39}$ CEBRIÁN, Juan L. A rede: como nossas vidas serão transformadas pelos novos meios de comunicação. São Paulo: Summus, 1998.

${ }^{40}$ CASTELL, 2006, p. 41.
} 
aparecem com implicações globais não só a título informacionais, mas em nível crítico e revolucionário $^{41}$. O espaço cibernético gera a possibilidade direta de articular a metamorfose dos conhecimentos compartilhados haja vista sua veiculação em tempo real de uma forma mundializada. Se a publicidade política ativa e estatal funcionava construindo maiorias legitimadoras de determinados projetos políticos, as redes sociais permitem a contra-opinião e a evidência de minorias que se interpõem como protagonistas da esfera pública ${ }^{42}$.

\section{Certeza e entendimento da opinião nas redes sociais}

A opinião pública após o impacto das redes digitais está marcada pela horizontal do conhecimento que embasa a opinião pública e a capacidade de sua publicação $^{43}$. A sociedade em rede amplifica a publicidade da opinião privada. Nesse contexto o transcendente na análise da opinião pública não é o espaço ou a dinâmica institucional a partir da qual se gera, mas o fato de os sujeitos de diversas índoles se relacionar como iguais em suas conexões. Porém, a questão central consiste em analisar a opinião pública como conhecimento que articula o parecer individual com uma objetividade intersubjetiva. Nesse sentido orienta-se aqui o enfoque teórico hegeliano o qual tem tido reconhecimento na contemporaneidade frente aos limites de uma opinião pública pensada em termos meramente individuais ${ }^{44}$. Essa referência a Hegel é importante quando as interpretações individualistas dos processos de opinião nas redes prevalecem e propalam a ideologia neoliberal obliterando desta forma os laços intersubjetivos ${ }^{45}$; subjacente a esta referência está a ideia que a filosofia hegeliana é eminentemente social e intersubjetiva.

Percebe-se que as opiniões veiculadas nas redes sociais consistem num conhecimento que se gera num espaço inicialmente privado de afirmação. As redes possibilitam a expressão democratizada das opiniões como certezas autorreferenciadas da realidade. Permitem expressar todas as opiniões com caráter de conhecimento acerca dos fatos ligados aos interesses comuns da sociedade, de modo que o que antes era prerrogativa só dum grupo de instituições agora está ao alcance de indivíduos variados. Os meios de validação tradicionais dum fato como a fotografia, som, testemunhas, etc., já não são mais domínios exclusivos de determinadas instituições, pois são compartilhadas livremente na internet. As redes têm modificado a homogênea sociedade de massa substituindo-a por uma sociedade heterogênea na qual as informações e opiniões são especializadas e diversificadas por ideologias, valores, gostos e estilos de vida ${ }^{46}$.

\footnotetext{
41 Cf. CUEVA, Javier. "Internet como entrono de la opinión pública: envolviendo derechos fundamentales en derechos ordinarios". Universidad Complutense de Madrid. http://pensamientopolitico.org/Descargas/RIPP07093115.pdf.

${ }^{42}$ CEBRIÁN, 1998, p. 87.

${ }^{43}$ CASTELL, 1998, p. 41.

${ }^{44}$ ACANDA, 2002, p. 171.

${ }^{45}$ CASTELL, 1998, p.198.

${ }^{46}$ Ibidem, p. 425.
} 
As redes suscitam a manifestação de preferências e concepções assim como a assimilação de grupos de intercâmbio e, por isso, oportunizam a capacidade de deliberação e de reafirmação de padrões estéticos, éticos e políticos dos sujeitos imersos nos fluxos comunicacionais. Elas potencializam a criação de referentes individuais a partir duma cosmovisão muito mais amplia ao expor uma variedade maior de padrões de existência. Essa possibilidade hipertextual gera uma renovada oralidade na publicidade $^{47}$. Em redes sociais como Facebook, a emissão dum conhecimento é expressa como estado privado e a mesma possibilita ferramentas de expressão individual de adesão ou execução de opiniões especificas. No Twitter o usuário individual tem a capacidade de converter em opinião compartilhada qualquer acontecimento ou impressão mediante interação por meio de poucas palavras compartilháveis e reproduzíveis.

Mas a possibilidade de geração e socialização direta da opinião privada surge num mundo permeado pela crise dos modelos culturais tradicionais de geração de identidade. O seguimento desta publicidade virtual está relacionado com um forte processo de individualização simbólica que pretendeu construir um universo individual como esfera autorreferencial ${ }^{48}$. A individualidade é reconhecida como esfera de afirmação do Eu e de um desenvolvimento não determinado pelas instituições estatais e coorporativas. As redes acentuam este caráter da vida privada ainda estando num espaço diretamente público. A simples afirmação individual traz consigo a possibilidade da substituição da vida real pela opinião privada $^{49}$, pois estas interações a partir do privado contêm quotas de poder nas decisões sobre os processos de geração e consumo de opiniões $^{50}$.

A massa infinita de conteúdo pode também gerar a autorreferencialidade na dialética privado-público do processo de opinião. O contínuo processo de expressão privada pode estar relacionado a uma alienação do Eu, um profuso falar com outros perante a incerteza da subjetividade. A massa de conhecimento gerada que tem adquirido o nome de "sociedade do conhecimento" não implica que esta seja uma sociedade da inteligência. Esta saturação contribui para a marginalização da certeza afirmativa do eu na utilidade imediata do conhecimento socializado. Um dos limites das opiniões nas redes a partir destas dinâmicas privadas é a incapacidade de ultrapassar o limite do inconsciente coletivo e da massa de informação socializada. Esse processo pode constituir uma esquizofrenia social onde o sujeito, a pessoa, perde importância e se perde no todo ${ }^{51}$.

Seguindo a análise hegeliana esta afirmação individual na utilidade autorreferencial limitaria o caráter público da opinião. Mas as redes desde sua própria constituição geram a evolução dessa certeza na interação com outros sujeitos. Os

\footnotetext{
${ }^{47}$ LÉVY, 2000, p. 14.

${ }^{48} \mathrm{~A}$ partir dos anos 70 surge, por exemplo, o movimento "A nova Era" como sustentação ideológica dum fornecimento do individualismo como valor fundamental a nível social. A esse processo se une o surgimento de teorias culturais pós-modernas. (PARENTI, M. La Batalla de la Cultura. La Habana: Ciencias Sociales, 2009, p. 125).

${ }^{49}$ CASTELL, 1998, p. 443.

${ }^{50}$ HERRERA, Yasmanys. Democratizar la información. Pieza clave para el cambio: Análisis de la contribución de la web 2.0 al proceso de democratización de la información. (Tesis de grado). 2014, p.160.

${ }^{51}$ KOLB, Anton. Cibernética: responsabilidade em um mundo interligado pela rede digital. São Paulo, Edições Loyola, 2001, p. 31.
} 
conhecimentos aparecem num primeiro momento como públicos ao conter um parecer não mediado, nem pelos Estados nem pelas corporações da comunicação pública. O processo de autorreferencialidade pressupõe o interagir com o outro e uma dinâmica de reconhecimento. Este não é mais um processo do Eu abstrato, senão de interação intersubjetiva. A publicidade nesta esfera volta ao exercício direto do cidadão com a horizontalização dos processos de opinião a partir da inusitada desterritorialização da opinião que permite o desafio da publicidade a partir da multiplicidade. Mas esse complexo sistema de mudanças não implica o caráter consciente desse interagir como construção dum conhecimento que contemple a objetividade; esse processo será o de uma evolução autoconsciente e consciente. A consciência salvará o indivíduo do processo de massificação.

Esta dialética entre opiniões esta mediada pela interação dos interesses privados e públicos no espaço intersubjetivo. A partir dela se questiona o caráter público daqueles espaços de socialização que respondem a interesses privados e coorporativos e, assim, define-se o antigo conflito entre publicidade como capacidade social de construção de relações de intercâmbio em interesses mútuos e o público é concebido como espaço de intercâmbio a partir do domínio de interesses privados. As redes põem em crise a individualização ao criar esferas de interação virtual que acrescentam exponencialmente a capacidade de interação na publicidade. A própria sociedade em rede contém como princípio a constituição intersubjetiva de todo processo social ${ }^{52}$. Ao mesmo tempo que a vida se virtualiza, a opinião afirma-se na certeza individual e nesse mesmo sentido se publiciza, pois tem que se inserir num espaço público de compartilhamento. A individualização entra em crise porque pressupõe a participação num espaço não privado. Por exemplo, a publicidade em rede tem definido dinâmicas familiares que a sociedade industrial de massa havia situado na esfera social do consumo ${ }^{53}$.

$\mathrm{Na}$ análise de Habermas a esfera pública entra em crise como espaço de resistência devido à filtragem, que um grupo reduzido, realiza da emissão de conhecimento, para um público de massa sem capacidade de interferência. Esse esquema não se ajusta a uma análise das condições de geração de opinião nas redes sociais, onde a sua emissão e distribuição é horizontalizada. A crítica de Habermas aponta a forte publicidade da sociedade burguesa e a partir desta demonstra o caráter não público da opinião pública gerada pelos meios de comunicação de massa que obedeciam a estratégias de dominação do espaço ao invés de sua democratização. Os novos meios de comunicação em rede, como nova esfera de articulação da publicidade da opinião pública, estão determinados pela articulação em torno do controle do público como relação social. Como ferramentas eles são um meio de expressão duma opinião gerada em espaços de poder. Nesse sentido as redes, na dispersão individual do cúmulo de informação numa publicidade múltipla, implicam a procura pela integração do individual no espaço público. Este processo aparece como a única fonte de integração frente a crise institucional e simbólica tradicional ${ }^{54}$.

\footnotetext{
${ }^{52}$ CASTELL, 1998, p. 41.

${ }^{53}$ CEBRIÁN, 1998, p. 14.

${ }^{54}$ LÉVY, 2000, p. 48.
} 
Este processo não implica a geração automática duma opinião pública. O interagir não privado tem desenvolvido dinâmicas contrárias a uma construção pública, tanto que Hegel pontuou que o movimento da autoconsciência não implica que a opinião alcance diretamente a objetividade. O processo de constituição da publicidade virtual tem sido base de empoderamento de identidades bipolares entre instrumentalismo e identidades abstratas. Este processo se encontra na base do surgimento de fortes radicalismos sectários aprofundando a reagrupação das pessoas em identidades primarias: religiosas, étnicas, territoriais, nacionais ${ }^{55}$. Por outra parte, a multiplicidade de opiniões compartilhadas tem gerado o limite particular das identidades. É significativo o papel da destruição de identidade que o "Pensamento Único" gerou a partir da subordinação da publicidade e das dinâmicas globais de significação, o que demonstrou o potencial conservador da opinião nas redes ${ }^{56}$. Uns dos elementos que resulta deste quadro é a contraposição entre privado e público nas redes sociais, embora o caráter público do acesso tenha como cenário a concentração de propriedade coorporativa (como é o caso de Twitter e Facebook). De um modo geral, pode-se dizer que estar nas redes sociais não significa isentar-se de conservadorismos e de outras insuficiências e patologias sociais que o usuário experimenta no mundo fora das redes, isto é, no mundo extravirtual.

Contudo a publicidade em rede pode representar também a subordinação da individualidade a uma racionalidade exterior na qual se perde o controle da opinião ${ }^{57}$. Porém a opinião nas redes pode constituir um sistema de contradições entre a autorreferencialidade e a subsunção do privado numa esfera intersubjetiva limitada. Por isso a opinião expressa e consumida nas redes precisa ainda das mediações intersubjetivas para conter os sentidos duma publicidade. Os sujeitos de opinião já põem em dúvida, dada a enorme avalanche de opiniões, o caráter público das opiniões expressa nestes meios demonstrando assim o caráter crítico da consciência quando questionam a validade das informações compartilhadas.

\section{A constituição da opinião pública}

Na Fenomenologia, Hegel coloca a autoconsciência como espaço onde a oposição entre certeza e verdade é ultrapassada na consciência. Hegel critica a filosofia moral de Kant porque nela a consciência projeta normas apenas a partir de um ponto de vista formal sem vinculação com a realidade dependendo da máxima de um sujeito e do princípio de universalização. Hegel pretende mostrar as contradições na visão moral do mundo. A seção do espírito engloba: a) o sujeito que se identifica com a esfera pública de maneira imediata; b) o sujeito que alienado de si mostra o indivíduo como Eu ativo, o "homo faber" que só conhece o que produz ${ }^{58}$; c) o sujeito moral burguês que realiza a "reconciliação" suprassumindo as contradições da pessoa do direito abstrato. O sujeito reúne em si a universalidade pública e a singularidade privada como certeza na ação moral. A esfera pública institucionalizada e a linguagem da opinião pública são reunidas na ação moral como consciência pública moral do indivíduo privado.

\footnotetext{
${ }^{55}$ É significativo o papel das redes na conformação de organizações como o Estado Islâmico. CASTELL, 1998, p. 41.

${ }^{56}$ RAMONET, Ignacio. Propagandas silenciosas. São Paulo: Vozes, 2002.

${ }^{57}$ CEBRIÁN, 1998, p. 22.

${ }^{58}$ BLOCH, Ernst. Sujeito-Objeto. Esclarecimentos sobre Hegel. Paris: Ed. Gallimard, 1977, p. 56-63.
} 
É sabida a superação de Hegel das limitações que a doutrina moral de Kant contém em termos de sociedade civil, publicidade e opinião pública ${ }^{59}$. A certeza-moral inicialmente é a certeza do conteúdo singular que acompanha a ação. A ação singular, uma vez reconhecida pelos outros, determina o momento formal do dever pela ação. O sujeito conhece sua própria convicção e esse conhecer é a "ipseidade" de todos. Assim, as pessoas privadas que formam o público partilham entre elas suas convicções e são reconhecidas em sua opinião pública.

A bela alma preserva sua universalidade contemplando sua pureza universal; falta-lhe a força para se tornar algo e para suportar o ser. Permanece no renunciar a seu Si. Hegel expõe "a certeza moral" e "a bela alma", a contradição do sujeito moral que agindo aliena-se e corre o risco de se perder como consciência singular num tipo de ação que falta sentido e conteúdo. Inversamente, o sujeito moderno pode cair numa ação oposta, fechando-se na sua consciência cheia de pensamento universal, mas ele é incapaz de sair de si por medo de perder suas convicções. Hegel mostra o indivíduo preso pelo imediato do homem privado e de suas necessidades, oposto ao herói que representa a esfera pública ou o lado universal do sujeito. É o sujeito que se opõe à singularidade da individualidade e pela ação pública ele pode afirmar sua universalidade. O herói é a encarnação reconciliada da ação privada e pública. $\mathrm{O}$ sujeito é reconhecido como singular na esfera da sociedade civil, ao mesmo tempo é reconhecido como universal na esfera pública ${ }^{60}$. Este duplo reconhecimento é a identidade entre o Eu e o Nós que é realizado no sujeito.

A partir daí a moral kantiana é criticada por Hegel por elaborar postulados morais formais, dualistas e não efetivos. Sua visão moral do mundo é um "dever ser" que leva a uma mudança sempre num além, e que Hegel chama uma má infinitude. A partir do posicionamento hegeliano compreendemos que as redes não podem limitar-se à afirmação individual nem devem ser guiadas por valores racionais substratos, porém devem ser um processo de confrontação crítica tendente à efetividade na ação; precisam ser redes que incluem numa dialética a efetividade da ação que não é somente opinião enquanto conhecimento senão ação moral enquanto inclusão da ação pública.

\section{O princípio da "publicidade" e a consciência dialética}

A opinião pública segundo Hegel é uma contradição que contém ao mesmo tempo a contingência e a necessidade misturadas em $\mathrm{si}^{61}$. Não é possível buscar na mesma um critério de verdade. A ciência ultrapassa o domínio da opinião pública $^{62}$. A teoria hegeliana ligada ao conceito de sociedade civil está

\footnotetext{
${ }^{59}$ ACANDA, 2002, p. 170; HABERMAS, 1994, p. 143.

${ }^{60}$ HEGEL, 1992, p. 579; p. 455-456.

61 "O que em nossos dias deve ser levado em conta não pode mais ser imposto pela força, nem mais pelo hábito ou o costume, mas deve ser admitido pela discussão e justificado por argumentos”. (HEGEL, G. W. F. Linhas Fundamentais da Filosofia do Direito ou Direito Natural e Ciência do Estado em Compêndio. Trad., notas, glossário e bibliografia de Paulo Meneses et al; e apres. de Denis Lerrer Rosenfield e de Paulo Roberto Konzen. São Paulo: Loyola; São Leopoldo: UNISINOS, 2010), § 301.

62 "As ciências, ao contrário, quando elas são, ao menos, ciências verdadeiras, não se situam no terreno das opiniões e [do ponto de] vista subjetivos. Seu modo de exposição não consiste mais na arte de
} 
cheia de contradições e não chega a resolver seus problemas. Para Hegel a opinião pública não suprime a desigualdade dos homens oriunda da natureza, ao contrário, ela a eleva ao nível da desigualdade de atitudes, da fortuna, e mesmo da cultura intelectual e moral. O diagnóstico revela um conflito de interesses que desabilita o interesse comum pretendido como universal.

O conceito contraditório de opinião pública é a consequência da desorganização da sociedade civil. O sistema contraditório das necessidades é polarizado em interesses particulares, a tal ponto que uma esfera pública das pessoas privadas, mesmo fazendo uso político de sua razão, conduziria à formação de simples opiniões, traduzindo vontades inorgânicas e massificadas dirigidas contra o Estado orgânico. Para evitar tais afrontamentos e a explosão da sociedade civil, é preciso instaurar vínculos corporativos no seu interior. Hegel toma assim suas distâncias em relação ao liberalismo e introduz no conceito de sociedade civil corretivos coorporativos a fim de limitar a esfera privada de tal modo que o conceito de esfera pública não corresponda mais à definição que se dá a respeito da teoria liberal.

A dimensão crítica da esfera pública desenvolve o princípio da "publicidade" que se opõe ao princípio do segredo praticado pelo soberano. Hegel neutraliza assim a ideia de uma esfera pública burguesa, pois a sociedade contraditória e anárquica não pode produzir esta esfera emancipada. As pessoas privadas autônomas constituídas em público que desenvolvem suas trocas não estão a ponto de converter a autoridade política em reino da razão. Permanecendo no conceito de opinião pública de Hegel, nosso pressuposto é que ela é uma contradição. Os momentos contraditórios da consciência demonstram a contradição da opinião pública ao longo da Fenomenologia. A descrição histórica da constituição da opinião pública a partir da instituição de uma esfera pública confronta a tese kantiana do princípio formal da publicidade. A opinião é a expressão e a consequência das contradições e dos problemas da sociedade civil, donde ela tira sua origem. A posição hegeliana refere-se à constituição da opinião pública no interior de um espírito público que é o verdadeiro e o universal princípio institucionalizado no espírito ético da família, da sociedade civil e do Estado. Hegel mostra na gênese do espírito público a constituição da opinião pública social.

A expressão "saber absoluto" enquanto "saber" não é para ser compreendido no sentido de uma pura interioridade racional sem efetivação histórica, e a qualificação "absoluto" atribuída ao saber não significa uma sorte de perfeição ou de realização de todas as formas possíveis de conhecimento ou de agir. Mas, o "saber absoluto" é a afirmação de um princípio de penetração de todas as figuras da consciência a fim de levá-las ao verdadeiro sentido ou a seu conceito. Hegel escreve a Fenomenologia a fim de compreender as contradições da modernidade. Insiste na sua proposta de uma emancipação progressiva do saber científico, da sociedade econômica e do espaço político que constituem, com efeito, as bases da opinião pública. O mundo tradicional, sob a perspectiva de Hegel, colapsou e o resultado é a crise de uma consciência dividida entre as exigências de uma opinião pública que submete tudo ao crivo da crítica e a aspiração a um sentido que possa dar unidade ao novo dado.

apresentações, de alusões, de meias palavras, de subentendidos, mas de uma expressão sem equívoco, precisa, sincera da significação e da importância do conteúdo. É por isso que elas não entram na categoria do que constitui a opinião pública”. (Ibidem, p. 321). 
O entendimento exerce seu poder de análise e de crítica em face de todas as representações "bem conhecidas"; ele separa e reflete o que outrora era a vida substancial, a realidade estável ou o pensamento não crítico. É a destruição das opiniões recebidas e o trabalho do entendimento que mede as evidências metafísicas e religiosas tradicionais a partir do sujeito dotado do poder de criticar e de opinar livremente. $\mathrm{O}$ homem encontra-se no mundo da finitude separado do sentido ontológico, um mundo da divisão sem reconciliação. Por oposição ao entendimento e aos seus processos analíticos, nasce um misticismo imediato que busca um acesso ao essencial no íntimo do coração e da subjetividade. É o refúgio romântico dos êxtases pseudo-místicos que buscam a satisfação na fusão com o todo e a união imediata com a divindade. Face à crítica da opinião que divide e instaura a oposição, essa consciência acaba por fechar-se na arbitrariedade da opinião contingente de seu interesse particular, pois recusando o diálogo e a troca das opiniões através da confrontação das diferenças, ela escapa ao discurso público que forma e educa a opinião subjetiva e individual à comunicação universal.

Hegel se opõe a um saber para o qual a verdade está no movimento que lhe permite compreender isoladamente apenas a si mesmo; é preciso que a consciência aceite efetivar-se historicamente. As contradições culturais da modernidade manifestam a gênese das experiências da consciência pública neste meio movediço da opinião. Esse caminho das oposições da consciência da opinião é a busca de uma lógica da experiência. Esta lógica começa com o indivíduo através do ato de opinar em que a questão da verdade e de seu reconhecimento desenvolve-se na experiência não ainda apreendida em seu conceito, pois a oposição do saber e de seu objeto, da consciência e da autoconsciência, e do sujeito e da substância permanece na contradição. Esta retomada lógica do movimento essencial da experiência compreende a verdadeira relação da objetividade e da subjetividade, do conteúdo e da forma que reconhece o movimento imanente da realidade e a modela desde o interior.

A instituição do espírito público é movimento de autodiferenciação, ato de colocar as contradições da cultura na diferença das opiniões, para refleti-las num processo que inclui ao mesmo tempo a liberdade subjetiva da consciência de opinar na mediação objetiva pública. A elevação ao conceito é um caminho na formação da consciência de opinar e a interiorização de todo o percurso fenomenológico que encontra sua realização quando a distância do saber e de seu objeto, da autoconsciência e a consciência é apreendida como imanente ao saber ${ }^{63}$. Este é o resultado dum processo de suprassunção do tempo e do conceito; o saber dialético da opinião pública é a relação da consciência que religa o pensamento às suas condições sócio-históricas como constituição do espírito público. A opinião pública sabe que seu acesso ou sua elevação ao conceito efetiva-se na gênese histórico-cultural, pois a opinião julga a tradição e a modernidade para reconciliá-las no saber absoluto.

A opinião pública insere-se no interior do novo princípio hermenêutico da realidade moderna que, para Hegel, é a razão especulativa capaz de

\footnotetext{
63 "A verdade é o conteúdo que na religião é ainda desigual à sua certeza. Mas esta igualdade consiste em que o conteúdo recebeu a figura do Si. Por isso, o que é essência mesma, a saber, o conceito, se converteu no elemento do ser-aí, ou na forma da objetividade para a consciência”. (HEGEL, 1992, p. 683).
} 
reconciliar o mundo e o absoluto, a efetividade histórica e o sentido eterno ${ }^{64}$. A originalidade da razão especulativa consiste em propor a reconciliação do conteúdo conteúdo substancial da tradição ontológica com a forma da modernidade crítica. $\mathrm{O}$ O saber contraditório da opinião pública encontra seu sentido no interior da razão razão especulativa que reconcilia a ontoteologia tradicional e o princípio da subjetividade moderna. Com efeito, o conteúdo substancial da opinião expressa-se de se de uma maneira representativa, e isso constitui sua contradição; é por isso que a opinião tem necessidade de manifestar seu conteúdo numa forma verdadeira.

A segunda parte do estudo do "saber absoluto" analisa o espírito sob a forma unificada do conceito. Muitas questões são postas a respeito desta parte, por exemplo, a "supressão do tempo". Esta não significa o acesso a um saber superior liberto da história, mas o tempo segundo Hegel é "o conceito que está ấ" "65; agora a consciência filosófica capta esses momentos na sua reflexividade ou na sua coextensividade especulativa.

O encadeamento das figuras da consciência e a articulação dos puros momentos do conceito guardam seus modos de organização específicos na constituição do "saber absoluto". Esse saber sendo atingido agora será ressignificado de modo essencial enquanto poder de se engajar na compreensão das diferentes figuras da civilização na sua contingência. O ponto de chegada do "saber absoluto" é, simultaneamente, o ponto de partida, pois o nível alcançado como "história concebida" comporta, de uma parte, o acontecer da história na contingência do fenômeno, e de outra, o conceber deste ato do acontecimento histórico, isto é, o conceito que compreende o sentido dos momentos históricos. O "saber absoluto" é a condição do sentido de todas as figuras ao longo de seu caminho fenomenológico. Ele determina no interior de cada figura a exigência conceitual de sua própria superação ou de sua suprassunção como figura ${ }^{66}$.

Com efeito, esta negação se encontra no interior da opinião pública, pois ela é a contradição mesma presente na consciência religiosa e na consciência histórica. A elevação da consciência ao saber e ao desenvolvimento do saber na fenomenalidade devem ser inteligidas juntas consideradas como significando a automediação e autorreflexão da opinião pública. O saber da opinião pública permite a esse mundo da consciência reconhecer-se como anterior à razão absoluta na qual não é a fenomenalidade que desaparece, mas a maneira abstrata que ela se vê e se compreende no ponto de partida. É por isso que a opinião pública tem por função permanecer no negativo; dito de outro modo, ela assume a tarefa de formação da consciência que consiste em interiorizar pela mediação o processo do espírito público.

O permanecer no negativo constitui o saber dialético da opinião, pois ela faz com que toda determinação "bem conhecida", fixa ou em repouso, entre num processo

\footnotetext{
64 "Em todos os tempos, a opinião pública foi um grande poder e é, particularmente, o caso de nossa época, em que o princípio da liberdade subjetiva tem tanta importância e significação". (HEGEL, 2010, § 316 - adição p. 318).

${ }_{65}^{65}$ HEGEL, 1992, p. 686.

66 'O 'saber absoluto' assume de tal modo, ao longo da obra, uma função de abertura; ele é o que fura a massificação do conhecimento representativo; é por ele que se opera esta valorização da contingência necessária, para que a consciência se desperte à inteligência e à feitura de uma história que só se pode penetrar graças a essencial fluidificação cuja responsabilidade é do conceito. Assim, ao antípoda de um acabamento da história, o "saber absoluto" é, ao contrário, o que torna possível o desenvolvimento sensato, através da negação inscrita no coração da realidade temporal". (LABARRIÈRE-JARCZYK. De Kojève a Hegel. Paris: Albin Michel, 1996, p. 230).
} 
dinâmico de diferenciação relacional, desencadeando um movimento de "polos em tensão, contraditórios e reconciliados, que funcionam em verdade, e entre os quais circula o sentido"; portanto, isso compreendido, não significa mais do que afirmar a força do negativo e da diferença na certeza de que somente o espírito pode afirmar seu poder unificador ${ }^{67}$. Este poder do negativo do fenômeno da consciência de opinar é a contradição que a constitui, e é justamente este poder da contradição que se determina como o movimento lógico da opinião pública.

O "saber absoluto" é a unificação das duas partes da Fenomenologia: a primeira envolve "o espírito na sua consciência" com os momentos da consciência, da autoconsciência, da razão e do espírito. A consciência realiza a experiência do objeto público que se torna autoconsciência opinante na contradição dos interesses privados e públicos e que encontra na razão a verdade de uma consciência pública. Ora, esta marcha da consciência do ato de opinar verifica-se historicamente a partir do espírito público. O saber absoluto efetiva a unificação de duas consciências. A consciência pública apresenta uma forma perfeita em busca do conteúdo, enquanto que a consciência crente propõe um conteúdo verdadeiro, mas apreendido sob a forma inadequada da representação. A primeira parte do "saber absoluto" mostra a articulação do movimento do espírito reconciliando a consciência e a autoconsciência ou a objetividade e a subjetividade. Esta unificação realiza-se do lado da consciência histórica onde a consciência religiosa encontra sua efetividade. A figura da "bela alma" exprime esta reconciliação na medida em que ela não pode se afirmar na sua abstração interior, mas aceita engajar-se e afirmar-se no estado de dizer sua opinião e de fazer a unidade do histórico e do religioso.

\section{Considerações finais - a dialética e a objetividade na opinião em rede}

O processo de constituição da opinião pública como temos descrito, tem sido afetado pela publicidade das redes digitais. Esta tem possibilitado a geração socializada de conhecimento, sua distribuição e consumo interativo. Esta interatividade, base da sociedade em rede onde o conhecimento e a informação afetam toda a reprodução social, implica a interação intersubjetiva como fato consuetudinário. Mas a socialização da possibilidade de opinar, de emitir conhecimento num processo supraindividual consuetudinário e interativo, não garante a objetividade dessa opinião. A natureza individual do fato de opinar leva a um alto grau de legitimação, como públicas, de simples opiniões individuais o grupais. Ao mesmo tempo as articulações que mediante esta virtualidade gera a publicidade da opinião, não contêm necessariamente em si a proeminência da publicidade da opinião. Os processos de compartilhamento no espaço virtual não asseguram o caráter público da opinião. A diversidade é um dos fatores mais relevantes deste processo em que a infinidade de interesses e opiniões relacionados torna complexa a conjunção da opinião pública.

\footnotetext{
67 "A atividade do dividir é a força e [o] trabalho do entendimento, a força maior e mais maravilhosa, ou melhor: o poder absoluto" [...]. "Este poder, não é como o positivo que se afasta do negativo, como quando nós dizemos que alguma coisa não é nada, ou falsa, e então, liquidamos com ela e passamos a outro assunto; mas ele não este poder senão enquanto ele olha esse negativo de frente [e] permanece junto dele. Esse permanecer é a força mágica que converte o negativo em ser”. (HEGEL, 1992, p. 93-94).
} 
A geração de conhecimento tem provocado um paradoxo na sociedade de informação, a saber, o acesso aos dados e a indiferença e incerteza acerca da objetividade dos mesmos ${ }^{68}$. A dinâmica autorreferenciada e a limitação numa identidade identidade parcial e utilitária da opinião, têm questionado o caráter objetivo do conhecimento publicado nas redes. Se os meios de legitimação da opinião têm sido sido globalizados, as dinâmicas descritas com anterioridade deixam clara a problemática problemática de como gerir um conhecimento objetivo acerca da opinião. A opinião opinião descreve, então, a contradição entre as dinâmicas privadas de geração do conhecimento e as públicas de sua legitimação como opinião objetiva. O caráter público da opinião está vinculado à capacidade de expressar um conhecimento objetivo a partir dum saber dialético que venha a suprassumir essa dualidade contraditória. Neste sentido as redes sociais da publicidade digital possibilitaram uma hipersensibilização do público, algo que não é possível na sociedade de massa onde existe apenas o domínio exclusiva de uma mídia manipuladora. Embora essa simples interconexão não represente a superação total das exclusões vivenciadas fora das redes, isto é, no mundo real. Além disso, há toda uma questão valorativa que gira em torno do modo como as relações nas redes são estabelecidas, ou seja, se isso é feito de modo respeitoso ou patológico. Por isso é fundamental o nicho cultural de normas de relacionamentos, valores de ação, tecnologias de resolução de conflitos e inovação participativa que possibilitem uma vivência respeitosa.

A opinião nas redes sociais permite a confluência de ação coordenada que tem sido fonte de coesão de movimentos sociais que têm ultrapassado as identidades sectárias. Esse processo tem se vinculado à geração de conhecimento objetivo; não é casual que em 1995 tenha surgido por exemplo um movimento como a "Verdade Absoluta", seita japonesa que tentava a concreção dum ser coletivo partir das identidades tecnológica ${ }^{69}$.

O compartilhamento de sentidos sobre problemáticas locais ultrapassando os limites territoriais e grupais tem sido uns dos elementos mais importantes do processo de articulação duma nova publicidade ${ }^{70}$. Mediante as dinâmicas de geração de informações dos meios de comunicação de massa a partir da década oitenta, têm surgido novas formas de articulação da sociedade civil gerando novas pautas de sentido. Unido à limitação do papel do Estado, a ampliação da sociedade civil tem construído uma multiplicidade de identidades e axiologias a partir de ações reivindicativas. Esse processo contestatório ao domínio do "pensamento único" fez surgir racionalidades alternativas a partir da defesa de valores como a solidariedade, respeito à diversidade e multiculturalismo ${ }^{71}$, processos que têm tido como centro a possibilidade publicitária das novas formas de conhecimento, comunicação e opinião em redes. Aliás, as dinâmicas globais de homogeneização cultural e axiológica demonstraram o potencial conservador das dinâmicas de opinião em redes ${ }^{72}$. Ao mesmo tempo serviu de catalisador do surgimento de movimentos de opinião contra a publicidade de massa, contestando

\footnotetext{
${ }^{68}$ GARCIA, Juan Antonio: "La opinión pública en la sociedad de la información: un fenómeno social en permanente cambio". http://dialnet.unirioja.es/servlet/articulo.p.281.

${ }^{69}$ CASTELL, 2006, p. 59.

${ }^{70}$ LÓPEZ, 2011, p. 236.

${ }^{71}$ CEBRIÁN. op.cit. p.153.

${ }^{72}$ RAMONET, 2002, p. 185.
} 
dinâmicas de reprodução do capital financeiro internacional, ações geopolíticas imperialistas e pautas de relacionamento relativas a questões étnicas, de gênero e etárias.

Exemplos diversos dessa articulação fazem reconhecer como elemento substancial da opinião pública a articulação do processo de conhecimento e seu compartilhamento conforme valores de identidades abrangentes ${ }^{73}$. Estes têm organizado a publicidade numa dialética de confluência de interesses privados e valores comuns. As redes têm servido para a mobilização da opinião pública em torno de valores de proteção ao meio ambiente, como alternativa à mídia de massa carregada de alusões ao consumo. A opinião a partir das redes tem possibilitado a movimentação das condutas privadas a partir duma mensagem pública usando as redes de Emails ou mais recentemente Twitter e Facebook, além de aplicativos de transmissão de mensagens em tempo real. De igual forma tem amplificado racionalidades econômicas alternativas e redes de economia solidária, ou a articulação de propostas como o Foro Social Mundial. Em 2003, o movimento contra a Guerra no Iraque utilizou as redes de correios eletrônicos e celular para a articulação da opinião pública, algo que se deu sem o apoio dos partidos políticos e dos meios de comunicação tradicionais. A conjunção abrangente de identidades, valores e concepções têm definido a nova fenomenologia da opinião pública. Um exemplo de luta clara entre a publicidade de massa e a publicidade de redes encontra-se no caso das eleições espanholas de $2004^{74}$. A livre emissão de opiniões e conhecimentos sobre os fatos interagiu num processo de confluência de valores e concepções que consumaram a construção duma opinião objetiva efetivada no espaço eleitoral ${ }^{75}$.

Em 2002 na Venezuela, a utilização do Twitter foi fundamental para a geração de conhecimento objetivo sobre os fatos do Golpe de Estado ao governo constitucional. A opinião pública nas redes socais foi a alternativa à desinformação dos meios de comunicação de massa alinhados ao Golpe, assim como está acontecendo aqui no Brasil no processo de Impeachment da Presidenta Dilma. Na Venezuela não foi somente um processo de mobilização dos grupos de apoio ao governo, senão também de articulação de grupos de oposição que não defenderam o Golpe. Neste casso o compartilhamento de valores democráticos fez que parte da oposição não prestasse apoio ao golpe, algo que demonstrou que esta virtualização da ação de opinar tem como elemento central a construção de uma opinião mediada intersubjetivamente sem a imposição de uma verdade hegemônica.

Em junho de 2013 no Brasil, as manifestações cidadãs conseguiram impor uma opinião pública por cima das estruturas de representação da publicidade de massa. Ambos os casos, o da Venezuela e o do Brasil, colocaram as redes sociais não apenas como meio de expressão e acesso ao conhecimento de dados econômicos e políticos, mas essencialmente como meios de articulação de ações públicas e democráticas.

Por fim, quanto à questão da interatividade e de seu regramento, a assunção de novas regras comportamentais e códigos de análises do conhecimento tem sido

\footnotetext{
${ }^{73}$ LÉVY, 2000, p. 98.

${ }^{74}$ No contexto das eleições as instituições da publicidade política ativa, geraram um discurso único e hegemônico, em quanto sua difusão entorno a fatos de interesse público. Nesse caso foram as redes de compartilhamento de informação pública digital, em especial as mensagens por celulares, as ferramentas a partir das quais se articulou uma versão objetiva dos fatos.

${ }^{75}$ LÓPEZ, 2011, p. 236.
} 
essencial na construção de ações para o acompanhamento das interações em redes sociais objetivando normatizar os crimes cibernéticos. Tal normatividade pressupõe valores vinculados à autogestão, veracidade de informações, coparticipação e relações respeitosas ${ }^{76}$. Por isso, a sustentabilidade da opinião pública nas redes sociais dependerá em parte do caráter ativo dos sujeitos da opinião na seleção e juízo acerca do conteúdo compartilhado ${ }^{77}$.

\section{Referências}

ACANDA, Jorge Luis. Sociedad civil y hegemonía. Habana: Centro de Investigación y Desarrollo de la Cultura Cubana Juan Marinello, 2002.

BAVARESCO, Agemir. Fenomenologia da Opinião Pública. São Paulo: Loyola, 2003.

BOURDIEU, P. La opinión pública no existe. Paris: Lestempsmodernes318, 1973.

CASTELL, Manuel. A sociedade em rede. São Paulo: Paz e Terra,2006.

Cebrián, Juan L. A rede: como nossas vidas serão transformadas pelos novos meios de comunicação. São Paulo: Summus, 1998.

MEDEIROS, Jackson da Silva. "Considerações sobre a esfera pública: redes sociais na internet e participação política". TransInformação. Campinas, 25(1):27-33, jan./abr., 2013.

DE LA CUEVA González-Cotera, Javier. "Internet como entrono de la opinión pública: envolviendo derechos fundamentales en derechos ordinarios". Universidad Complutense de Madrid.http://pensamientopolitico.org/Descargas/RIPP07093115.pdf.

GABOARDI, E. A. A fenomenologia do espírito de Hegel: uma introdução à seção consciência. Porto Velho: Edufro, 2013. v. 1. 130p.

GABOARDI, E. A. O papel da contradição na experiência de determinação da verdade na certeza sensível e na percepção da Fenomenologia do Espírito de Hegel. Anais da 25a RBA Saberes e práticas antropológicas desafios para o século XXI, v. 1, p. 62-73, 2008.

GALINDO, Juan Antonio: "La opinión publica en la sociedad de la información: un fenómeno social en permanente cambio".http://dialnet.unirioja.es/servlet/articulo?codigo=3813224.

HABERMAS, J. Historia y critica de la opinión pública. Barcelona: Ediciones G. Gili, S.A, 1994.

HABERMAS, J. El discurso filosófico de la modernidad. Madrid: Taurus, 1993.

HABERMAS, J. Textos y contextos. Barcelona, Ariel, 1991.

HEGEL, G. W. F. Fenomenologia do Espírito. Petrópolis: Vozes, 1992.

HEGEL, Georg Wilhelm Friedrich. Linhas Fundamentais da Filosofia do Direito ou Direito Natural e Ciência do Estado em Compêndio. Trad., notas, glossário e bibliografia de Paulo Meneses et al; e apres. de Denis Lerrer Rosenfield e de Paulo Roberto Konzen. São Paulo: Loyola; São Leopoldo: UNISINOS, 2010.

HERRERA Borrero, Yasmanys. Democratizar la información. Pieza clave para el cambio: Análisis de la contribución de la web 2.0 al proceso de democratización de la información. Tesis de grado, 2014.

HUERTA Vilchis, Fernando: "Opinión Pública y Nuevas Tecnologías El impacto de las nuevas tecnologías en la opinión pública entre jóvenes mexicanos". IV Congreso Latinoamericano de Opinión Pública de WAPOR Belo Horizonte

Brasil.http://waporbrasil.ufmg.br/papers/Fernando_Huerta_Vilchis_.pdf.

HYPPOLITE, J. Gênese e estrutura da Fenomenologia do espírito de Hegel. Trad. de Sílvio Rosa Filho (Coord.). São Paulo: Discurso Editorial, 1999.

\footnotetext{
${ }^{76}$ SAMPEDRO, Víctor; Resina de la Fuente, Jorge: “Opinión pública y democracia deliberativa en la Sociedad Red". Revista Ayer. 80/2010 139-162, p.151.

${ }^{77}$ LÓPEZ, 2011, p. 237.
} 
INWOOD, M. Dicionário Hegel. Trad. de Álvaro Cabral. Rio de Janeiro: Jorge Zahar Editor, 1997.

KASTRUP, Virginia. Novas tecnologias cognitivas: o obstáculo e a invenção. In: LÉVY, Pierre. Ciberespaço: um Hipertexto. Porto Alegre: Artes e Oficio, 2000.

KOLB, Anton. Cibernética: responsabilidade em um mundo interligado pela rede digital. São Paulo, Edições Loyola, 2001.

LÉVY, Pierre. Ciberespaço: um hipertexto. Porto Alegre: Artes e Oficio, 2000.

LÓPEZ García, Guillermo. "Comunicación en red y mutaciones de la esfera pública" http://www.ehu.eus/zer/hemeroteca/pdfs/zer20-11-lopez.pdf.

LOSURDO, D. Hegel Marx e la tradizione liberale. Roma: Editori Riuniti, 1998.

MENESES, Paulo. Para ler a Fenomenologia do Espírito - Roteiro. São Paulo: Loyola, 1992. MALAGONE Pimenta, Lidiane. "A formação da opinião pública e as inter-relações com a mídia e o sistema político”. Relações Públicas e Mestre em Comunicação Midiática pela Unesp.http://www.compolitica.org/home/wp-content/uploads/2011/01/sc_jp-lidiane.pdf.

MARCUS, George E; Fischer, Michael M.J: Anthropology as Cultural Critique: an experimental moment in the human sciences. Chicago: The university of Chicago Press, 1986.

MEDEIROS, Priscila Muniz de. "Mídias Sociais e a Influência da Opinião Pública nas Tomadas de Decisão da Esfera Privada: Os Protestos Contra o Uso de Peles pela Indústria da Moda". Intercom - Sociedade Brasileira de Estudos Interdisciplinares da Comunicação XIII Congresso de Ciências da Comunicação na Região Nordeste - Maceió - AL - 15 a 17 de junho 2011112 Universidade Federal de Pernambuco, Recife, PE.http://intercom.org.br/papers/regionais/nordeste2011/resumos/R28-1014-1.pdf.

MUÑ̃Z Alonso, A. Opinión Pública y comunicación política. Madrid: EUDEMA, 1990.

NOBREGA, F. P. Compreender Hegel. São Paulo: Loyola, 2009.

OLIVEIRA, M. A. A liberdade como síntese de opostos: transcendência, engajamento e institucionalidade. In: Revista Veritas, Porto Alegre, vol. 44, n. 4, dez de 1999, p. 1019 a 1040.

OLIVEIRA, M. A. Tópicos sobre dialética. Porto Alegre: EDIPUCRS, 1996. (Coleção Filosofia, 51).

PARENTI, M. La Batalla de la Cultura. La Habana: Ciencias Sociales, 2009.

RAMONET, Ignacio. Propagandas silenciosas. São Paulo: Vozes, 2002.

ROSA, M. A reputação sob a lógica do tempo real. Revista Brasileira de Comunicação Organizacional e Relações Públicas, São Paulo, n. 7, p. 60-69, 2007.

BLANCO, Víctor Sampedro; FUENTE, Jorge Resina de la. "Opinión pública y democracia deliberativa en la Sociedad Red”. Revista Ayer 80/2010 139-162. ISSN: 1134-2277.

SANTOS, J. H. Trabalho e riqueza na Fenomenologia do espírito de Hegel. São Paulo: Loyola, 1993.

TAYLOR, Charles. Hegel. São Paulo: É Realizações Editora, 2013. 